\title{
SEASONAL AND REGIONAL VARIATIONS OF NORTHERN HEMISPHERE SEA ICE AS ILLUSTRATED WITH SATELLITE PASSIVE-MICROWAVE DATA FOR 1974
}

\author{
by \\ C.L. Parkinson, J.C. Comiso, H.J. Zwally, D.J. Cavalieri, P. Gloersen \\ (Laboratory for Oceans, NASA/Goddard Space Flight Center, Greenbelt, MD 20771, U.S.A.) \\ and \\ W.J. Campbell \\ (U.S. Geological Survey, University of Puget Sound, Tacoma, WA 98416, U.S.A.)
}

\begin{abstract}
A detailed description of the seasonal cycle of Northern Hemisphere sea ice for 1974 is provided by the passive microwave data from the Nimbus 5 Electrically Scanning Microwave Radiometer (ESMR). Sea ice extent has been mapped and analyzed in eight regions of the Arctic and marginal seas. In the seasonal sea ice areas, the ice concentration is also mapped, whereas in areas of first-year and multiyear ice mixtures, the corresponding mapping is of a parameter representing a combination of ice concentration and multiyear ice fraction. The total monthly ice extent increased from a sharp minimum of $7.6 \times 10^{6} \mathrm{~km}^{2}$ in September, when the ice pack was mostly confined to the central Arctic Ocean and portions of the Greenland Sea, Kara Sea, and Canadian Archipelago, to a broad maximum of $14.4 \times 10^{6} \mathrm{~km}^{2}$ in March, when the ice cover was nearly complete in the Arctic Ocean, Hudson Bay, Kara Sea, and Canadian Archipelago and was extensive for large portions of the other peripheral seas and bays. In the areas of seasonal sea ice coverage, the average ice concentration was approximately $75 \%$ in winter, which is close to the values observed in the Southern Ocean and significantly less than the greater-than- $95 \%$ concentrations observed in the central Arctic Ocean and Hudson Bay, where the ice packs are constrained by land boundaries. Midwinter decreases in ice extent for 1-2 months are noted in the regions of the Greenland Sea and the Kara and Barents Seas.
\end{abstract}

\section{INTRODUCTION}

Data collected by the Electrically Scanning Microwave Radiometer (ESMR) on board the Nimbus 5 satellite from its launch in December 1972 through most of the next four years provide the earliest all-weather, all-season imagery of global sea ice. For 39 months of the four-year period, good quality Northern and Southern Hemisphere data were obtained, at a wavelength of $1.55 \mathrm{~cm}$ and a resolution of about $30 \mathrm{~km}$, allowing a detailed description of the seasonal cycle of sea ice conditions and the interannual variations within that cycle over the period 1973-1976. The Southern Hemisphere data were compiled into an Antarctic sea ice atlas by Zwally and others (1983), and the Northern Hemisphere data have been compiled into an Arctic sea ice atlas by Parkinson and others (1987). This paper describes some of the results obtained for the Northern Hemisphere for the year 1974, which is the year with the most complete ESMR data set.

ESMR data have been used in several previous studies to analyze ice conditions in the Northern Hemisphere, including work by Crane and others (1982), Carsey (1982), and Campbell and others (1984). Interested readers are referred to those articles and the Arctic atlas itself for an extensive bibliography.

The value of the ESMR data for sea ice studies derives from the large contrast in microwave emissivities between sea ice and open water. At the $1.55 \mathrm{~cm}$ wavelength of the ESMR instrument, open water has an emissivity of approximately 0.44 , whereas sea ice has an emissivity of 0.80 to 0.97 , depending upon the composition and surface characteristics of the ice. Although the large range in sea ice emissivities introduces an ambiguity in sea ice concentration calculations from the ESMR brightness temperature data, the large contrast between the 0.44 emissivity of water and the $0.80-0.97$ range for sea ice enables a ready determination of the location of the sea ice edge from the ESMR data.

The most important contrast in sea ice emissivities for this study is the contrast between the emissivity of firstyear ice and the emissivity of multiyear ice, the latter being defined as ice having survived a summer melt period. In winter, first-year ice has an emissivity of approximately 0.92, whereas multiyear ice has an emissivity of approximately 0.84 . The lowered emissivity of multiyear ice derives in large part from the desalination produced by brine drainage. During summer, surface characteristics tend to dominate the microwave emission, of ten making the two ice types indistinguishable. This would assist the determination of ice concentrations from the microwave data except for the fact that the varied surface characteristics of the ice can produce a wide range in microwave emissivities. For instance, large-scale melt ponding reduces the emissivity whereas wet snow increases the emissivity. Nonetheless, the summertime sea ice emissivities remain predominantly in the range 0.80 to 0.97 (Mätzler and others 1983; Parkinson and others 1987).

\section{SEASONAL SEA ICE CYCLE}

Fig.1 shows monthly averaged ESMR brightness temperature data mapped and color-coded onto polar stereographic projections for March, June, September, and December, 1974, revealing the seasonal cycle of Northern Hemisphere sea ice coverage. The low microwave emissivity of open water leads to brightness temperatures over open water predominantly in the range $130-150 \mathrm{~K}$, while the higher microwave emissivity of sea ice leads to brightness temperatures exceeding $200 \mathrm{~K}$. Intermediate values within the sea ice region indicate mixtures of sea ice and open water. The sea ice edge is readily apparent on these images at the occurrence in ocean regions of the sharp color gradient from the grays of open water to the oranges, browns, and reds of the sea ice region. Ice sheets, such as the Greenland ice sheet in the lower center of the images of Fig.1, have microwave brightness temperatures predominantly in the range $150-200 \mathrm{~K}$, whereas other land surfaces have microwave brightness temperatures predominantly exceeding $230 \mathrm{~K}$.

The large contrast in microwave emissivities between sea ice and open water enables a conversion of the ESMR brightness temperatures to sea ice concentrations (percentages of the ocean area covered by sea ice) as long as all sea ice 

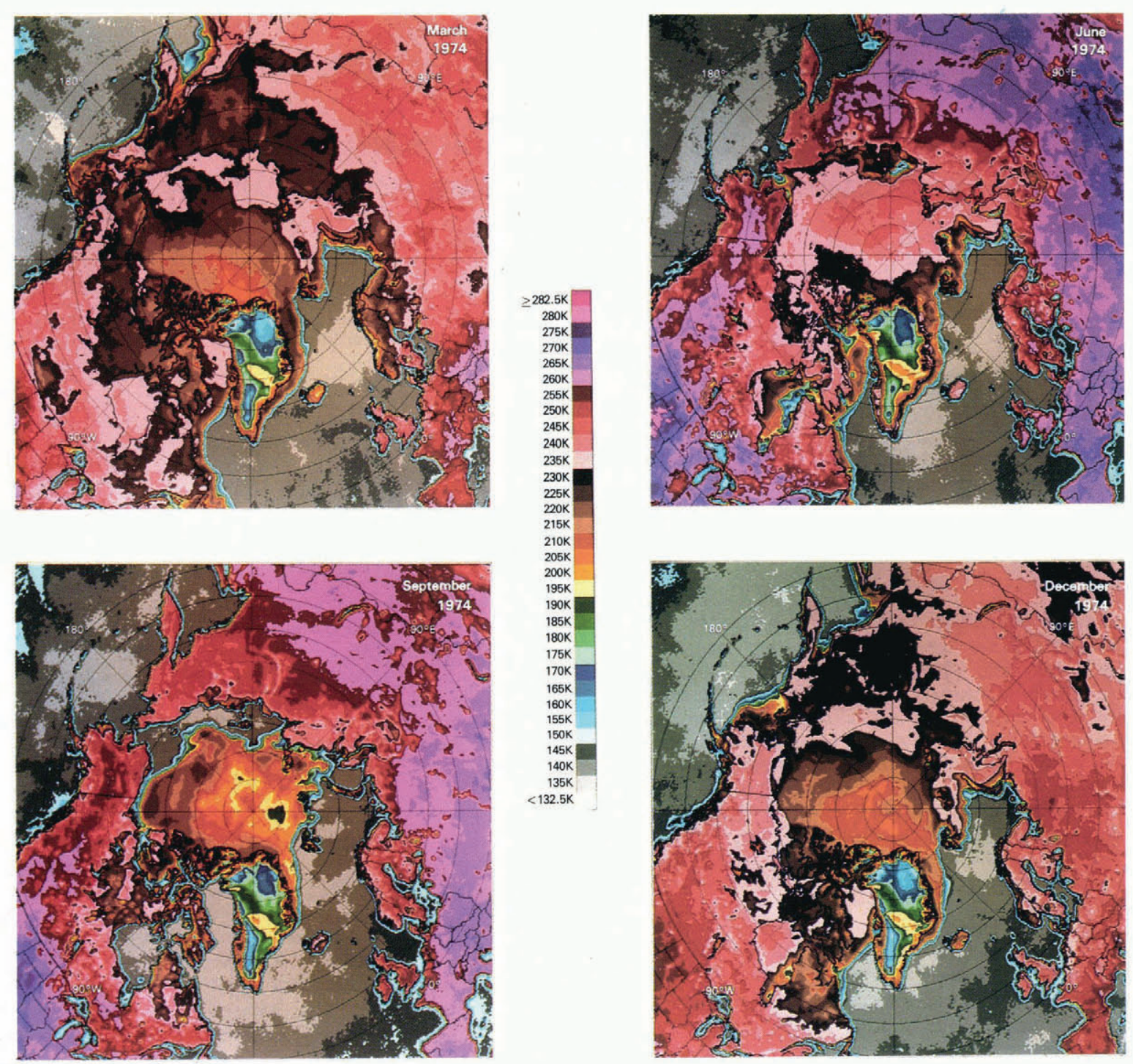

Fig.1. Mean monthly brightness temperatures from the Nimbus 5 ESMR for March, June, September, and December 1974

in the field of view has approximately the same emissivity. This is the case throughout most of the Southern Ocean and in many of the seas and bays peripheral to the Arctic Ocean, where the ice is predominantly first-year sea ice, with an emissivity near 0.92 . In such a case, the sea ice concentration, $\mathrm{C}$, can be calculated as:

$$
C=\frac{T_{B}-T_{o}}{\epsilon_{I} T_{e f f}-T_{0}}
$$

where $T_{B}$ is the microwave brightness temperature, $\epsilon_{I}$ is the emissivity of ice (taken as 0.92 for first-year ice), $T_{\text {eff }}$ is the effective radiating temperature of the ice, and $\mathrm{T}_{0}$ is the average observed brightness temperature over open ocean. For the calculations here, a constant value of $138.3 \mathrm{~K}$ has been used for $\mathrm{T}_{0}$. This value was determined from the ESMR data as an average open water value in the north polar region over the 1973-1976 period. (In the Southern Hemisphere a somewhat lower value of $135 \mathrm{~K}$ was used, again determined from the ESMR data. In both cases, these observed brightness temperatures include an atmospheric component.) $\mathrm{T}_{\text {eff }}$ is calculated as follows from mean monthly climatological air temperatures, $\mathrm{T}_{\text {air }}$ :

$$
\mathrm{T}_{\text {eff }}=\mathrm{T}_{\mathrm{air}}+\mathrm{f}\left(\mathrm{T}_{\mathrm{F}}-\mathrm{T}_{\text {air }}\right)
$$

where $\mathrm{T}_{\mathrm{F}}=271.16 \mathrm{~K}$ is the freezing point of sea water and $f=0.25$ is a parameter determined empirically from observed data. The use of mean climatological data in Equation 2 could result in ice concentration errors as large as $20 \%$. Further details can be found in Parkinson and others (1987).

In the Arctic Ocean itself, and some of the immediately adjacent waters, there is a large multiyear ice component, with an emissivity near 0.84 , in addition to first-year ice, with an emissivity near 0.92 . In these areas, sea ice concentrations cannot be calculated directly with Equation 1, although they can be calculated in a similar fashion from the brightness temperatures as a function of the fraction, $F_{M Y}$, of the ice cover which is multiyear ice:

$$
C=\frac{T_{B}-T_{O}}{F_{M Y} \epsilon_{I M}\left(T_{e f f}\right)_{M}+\left(1-F_{M Y}\right) \epsilon_{I}\left(T_{e f f}\right)_{F}-T_{0}}
$$

where $\epsilon_{I M}$ is the emissivity of multiyear ice, and $\left(T_{\text {eff }}\right)_{M}$ and $\left(\mathrm{T}_{\text {eff }}\right)_{\mathrm{F}}$ are the effective radiating temperatures of the multiyear ice and first-year ice respectively.

The brightness temperature data of Fig.1 have been converted to sea ice concentrations, using Equations 1-3. The resulting sea ice concentrations are presented in colorcoded images in Fig.2. Equation 3 is depicted on this figure by a nomogram relating the color scale, multiyear ice fraction, and sea ice concentration.

Before describing the sea ice cycle revealed in Figs 1 and 2 , one further set of images will be presented. These 

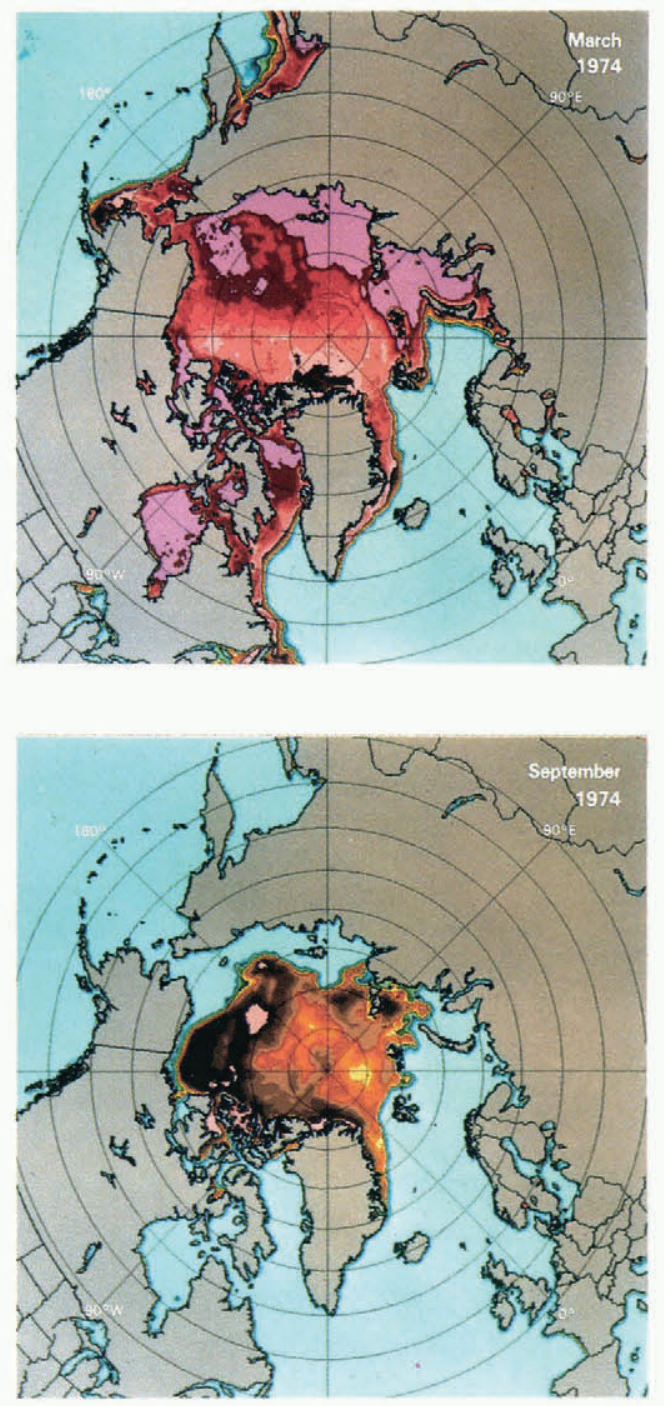
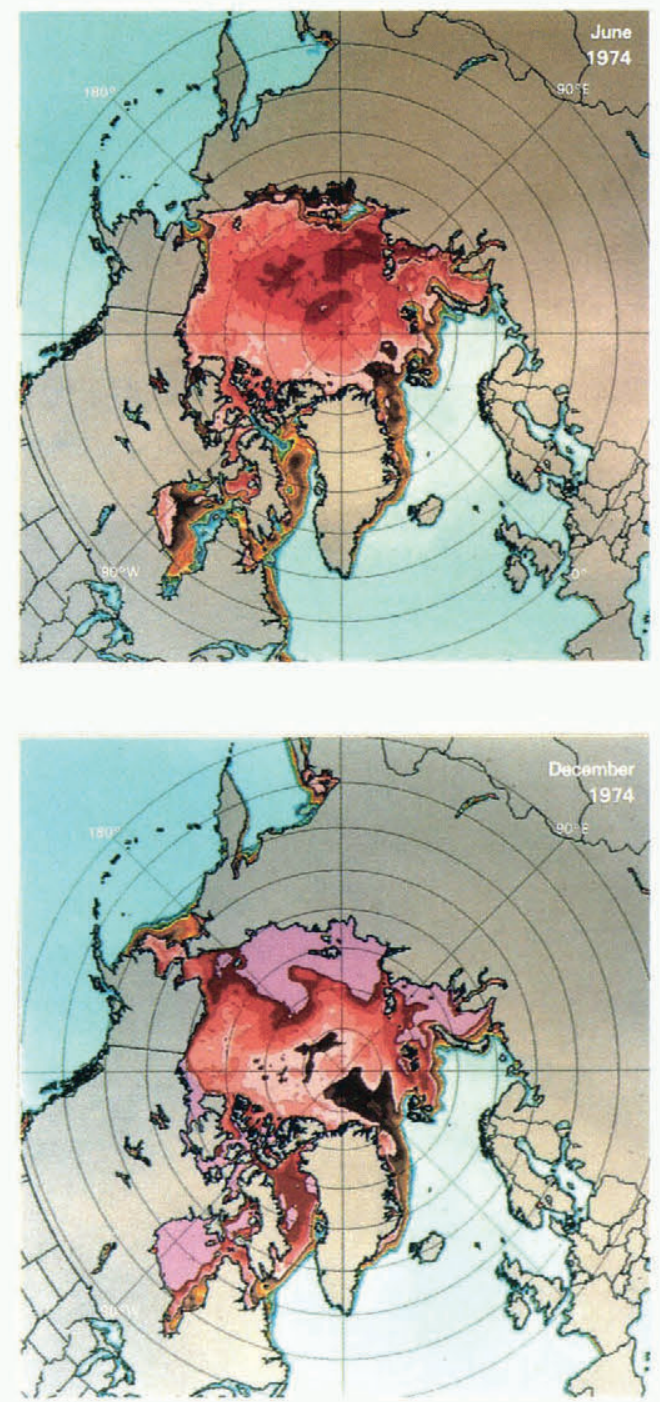

Fig.2. Mean monthly sea ice concentrations, calculated from Nimbus 5 ESMR brightness temperatures and mean monthly climatological atmospheric temperatures, for March, June, September, and December 1974. The nomogram in the center relates the color scale to the total ice concentration and the fraction, $\mathrm{F}_{\mathrm{MY}}$, of multiyear ice.

are monthly differences, calculated from the monthly averaged ice concentrations by subtracting the concentrations in one month from those in the subsequent month. By color coding positive values as blues and greens and negative values as reds, purples, and oranges, the growth and decay regions become immediately identifiable on these monthly difference maps. The full 1974 annual cycle of monthly differences is presented in Figs 3 and 4. The predominance of blues and greens in the images from September-October through January-February and the predominance of reds, purples, and oranges from April-May through July-August clearly distinguish the growth and decay seasons and identify August and September as the months of minimum ice cover and February, March, and April as the months of maximum ice cover.

Figs 1-4 together provide a detailed depiction of the full annual cycle of sea ice coverage in the Northern Hemisphere for 1974. In March, at the time of maximum ice extent, the ice cover was nearly complete in the Arctic Ocean, Hudson Bay, the Kara Sea, and the Canadian Archipelago, and was extensive for large portions of the other peripheral seas and bays (Figs 1 and 2). The springtime retreat of the ice edge in 1974 began first in the Sea of Okhotsk and the southern Greenland Sea and later in the Bering Sea, Baffin Bay, Hudson Bay, the northern Greenland Sea, and the Barents Sea (Fig.3). In September, at the time of minimum ice extent, the ice pack was mostly confined to the central Arctic Ocean and portions of the Greenland Sea, the Kara Sea, and the Canadian Archipelago. Essentially no ice remained in the Bering Sea, Hudson Bay, the Sea of Okhotsk, or Baffin Bay/Davis Strait (Figs 1 and 2). Noticeable autumn ice-edge advance began first in the Greenland Sea, between August and September, then became apparent throughout the remainder of the ice-covered region between September and October (Fig.4). These basic features of the annual cycle of sea ice are fairly consistent over the four years of ESMR data, 1973-1976, although with differences in specifics, as detailed in Parkinson and others (1987).

The monthly averaged ice concentration data have been used to quantify the annual cycle of ice extents and of ice within various ice concentration classes. Specifically, the data have been spatially integrated over the Arctic Ocean and many peripheral seas and bays (see Fig.5) to determine the area of the ice cover as a function of time (upper left diagram of Fig.6). For each month, the area of icecovered ocean (termed the total ice extent) is calculated by summing the areas of all map elements having at least $15 \%$ ice coverage. The area of an individual map element is approximately $30 \times 30 \mathrm{~km}$. Labelling as "pseudo ice concentrations" the ice concentrations calculated from Equation 1 with an emissivity $\epsilon_{\mathrm{I}}$ of 0.92 , the areas of the ocean covered by ice of at least $35 \%, 50 \%, 65 \%$, and $85 \%$ pseudo ice concentration are determined by summing the areas of all map elements having at least those respective percentages of pseudo sea ice coverage. Because of the sharpness of the 

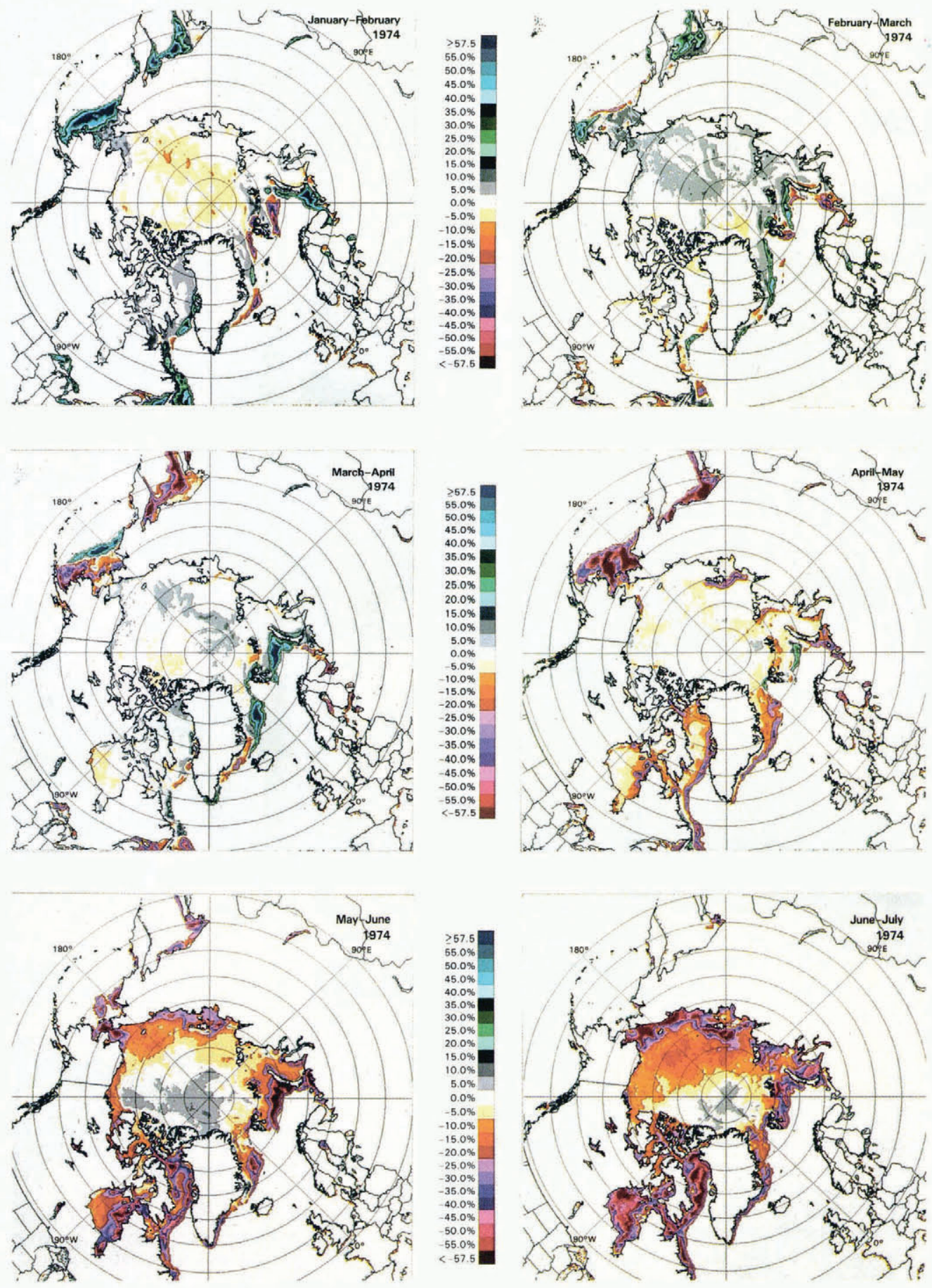

Fig.3. Sea ice concentration differences between consecutive months, from January-February 1974 through June-July 1974. Differences are calculated such that concentrations for the first month are subtracted from those for the subsequent month. 

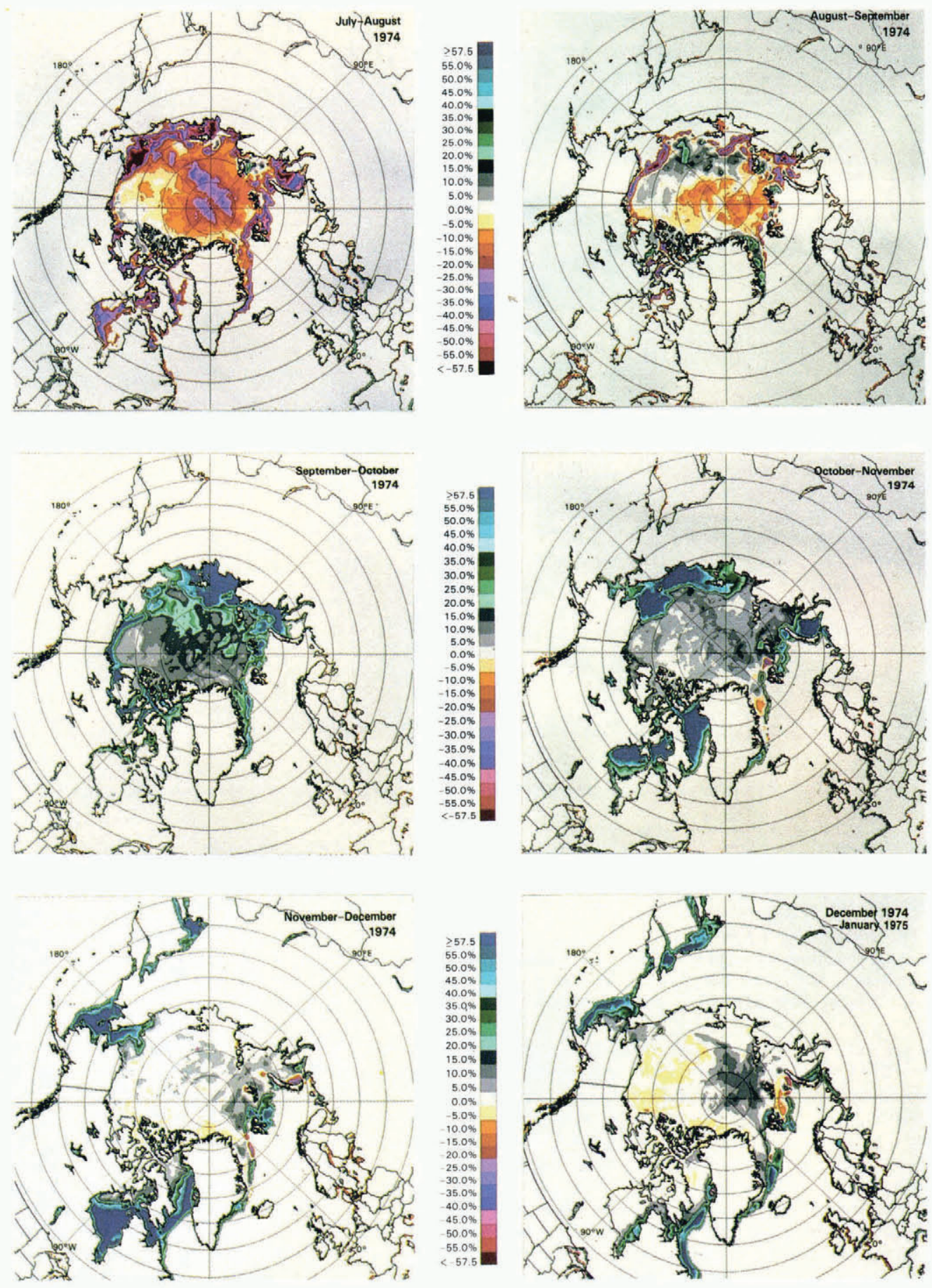

Fig.4. Sea ice concentration differences between consecutive months, from July-August 1974 through December 1974 to January 1975. Differences are calculated such that concentrations for the first month are subtracted from those for the subsequent month. 


\section{ARCTIC SEA ICE REGIONS}

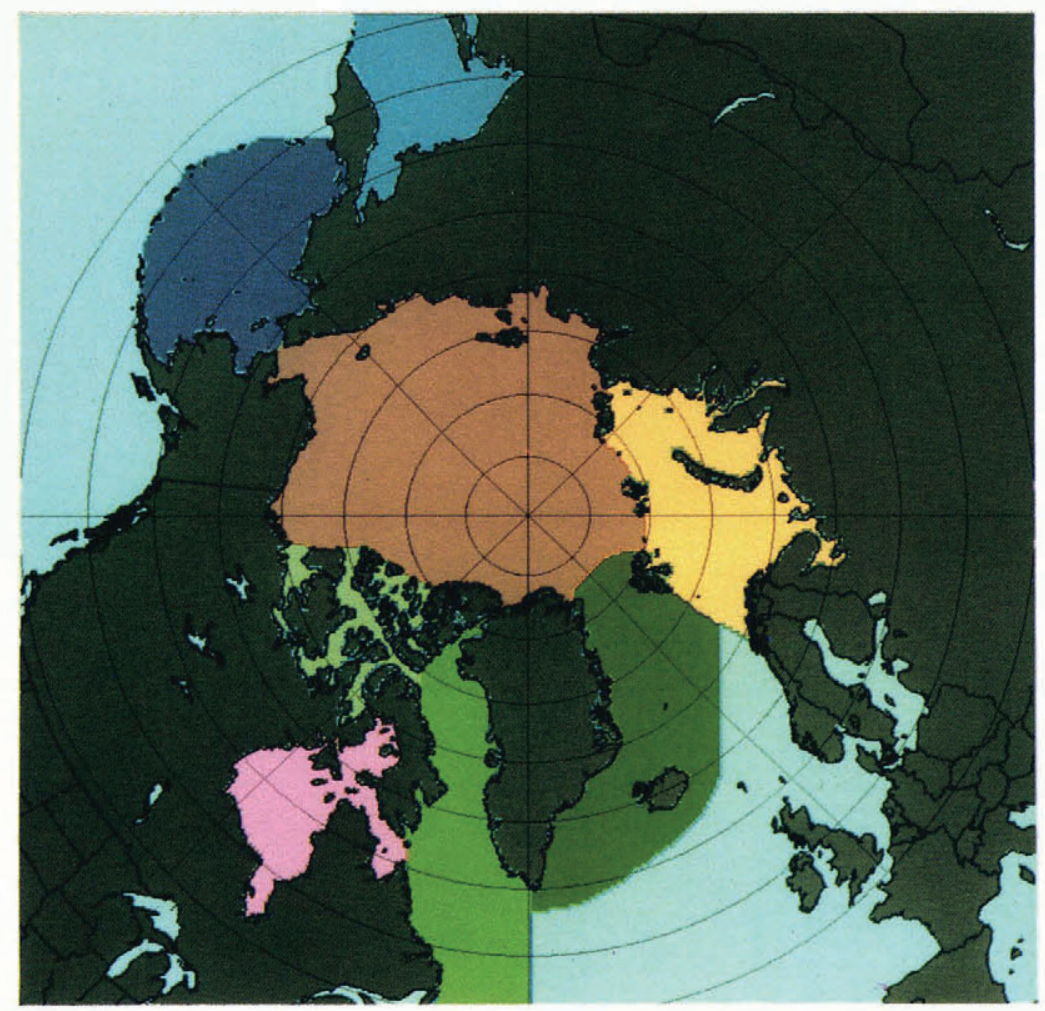

SEA OF OKHOTSK

BERING SEA

\section{HUDSON BAY}

BAFFIN BAY/DAVIS STRAIT

GREENLAND SEA

KARA AND BARENTS SEAS

ARCTIC OCEAN

CANADIAN ARCHIPELAGO

Fig.5. Regions identified for analysis and for calculation of areal ice coverages.

ice edge and its weak sensitivity to the ice emissivity, it was not felt necessary to attach the adjective "pseudo" in the case of the $15 \%$ curve. The upper left diagram of Fig. 6 also includes the area obtained by summing the products of the pseudo ice concentration and the geographic area of each map element. These are termed "pseudo actual ice areas."

Monthly average ice extents in 1974 increased from a minimum of $7.6 \times 10^{6} \mathrm{~km}^{2}$ in September to a maximum of $14.4 \times 10^{6} \mathrm{~km}^{2}$ in March (Fig.6). The maximum is broad, with February, March, and April all having ice extents between 14.3 and $14.4 \times 10^{6} \mathrm{~km}^{2}$ and with December, January, and May also having extents greater than $12.8 \times$ $10^{6} \mathrm{~km}^{2}$. The minimum is much sharper, with the extents in August and September, 8.1 and $7.6 \times 10^{6} \mathrm{~km}^{2}$ respectively, being significantly less than the extent in any other month. The annual cycles for the other ice concentration classes are similar to the cycle for the ice extent, with the various curves running almost parallel for much of the year (Fig.6). In August, less than $1000 \mathrm{~km}^{2}$ contain ice with pseudo ice concentration exceeding $85 \%$.

\section{REGIONAL DIFFERENCES}

Eight regions covering most of the Northern Hemisphere sea ice area have been selected for individual analysis. These are the Arctic Ocean, the Sea of Okhotsk, the Bering Sea, Hudson Bay, Baffin Bay/Davis Strait, the Greenland Sea, the Kara and Barents Seas, and the Canadian Archipelago (Fig.5). The same set of calculations used to create the upper left diagram of Fig. 6 have been performed on the data for each of the eight regions, with the results also presented in Fig.6. In the cases of regions with almost exclusively first-year ice, the qualifier "pseudo" is not felt necessary and so has been omitted from the plots and the discussion.

The regions where the ice cover essentially goes to zero in summer are the Sea of Okhotsk, the Bering Sea, Hudson
Bay, and Baffin Bay/Davis Strait. The seasonal and interannual variabilities of the ice covers in these seasonal sea ice zones reflect the variabilities of the regional meteorology and oceanography, making the wintertime ice covers of the Sea of Okhotsk and the Bering Sea, for instance, far more variable than the ice cover of Hudson Bay. The Bering Sea ice area increases sharply from January to February, increases only slightly from February to March (the ice extent, or $\geqslant 15 \%$ ice concentration class, actually decreases slightly), and, except for the $\geqslant 15 \%$ and $\geqslant 35 \%$ ice concentration classes, decreases from March to April (Fig.6). This contrasts with the rapid growth of the Sea of Okhotsk ice cover from January to March and the subsequent rapid decay from March until the end of the season (Fig.6). Such regional differences, as well as interannual differences, between the ice covers of the Bering Sea and the Sea of Okhotsk are the subject of recent air-sea-ice interaction studies (e.g., Cavalieri and Parkinson in press; Parkinson and Gratz 1983).

Hudson Bay and Baffin Bay/Davis Strait show less wintertime variability than the Bering Sea, partly because of being largely surrounded by land and therefore not being as susceptible to the influences of the open ocean. The ice covers of both regions grow largely from the northwest toward the southeast, with the most rapid growth occurring during October/November (Figs 4 and 6). By December, the entire Hudson Bay region fills with ice, resulting in the uniform ice area calculated for the region throughout the winter months (Figs 2 and 6). Baffin Bay/Davis Strait has a broad opening to the south and is subject to some variability as indicated in Figure 6 . The sea ice covers of both these regions survive much later in the season than do the ice covers of the Bering and Okhotsk Seas (Figs 2 and 6).

The remaining four regions each have large multiyear ice components, with considerable ice amounts remaining during the summer months. The Greenland Sea has a large influx of multiyear ice from the Arctic Ocean due to the 


\section{ALL REGIONS}

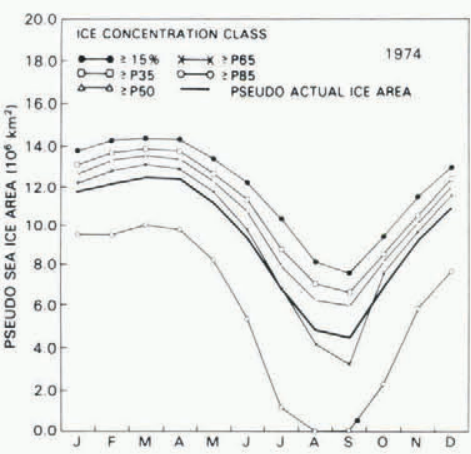

HUDSON BAY

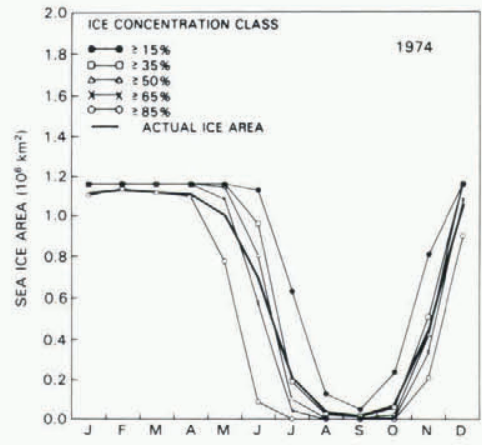

SEA OF OKHOTSK

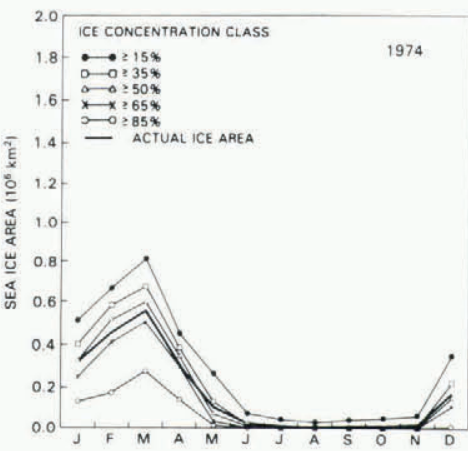

BAFFIN BAY/DAVIS STRAIT

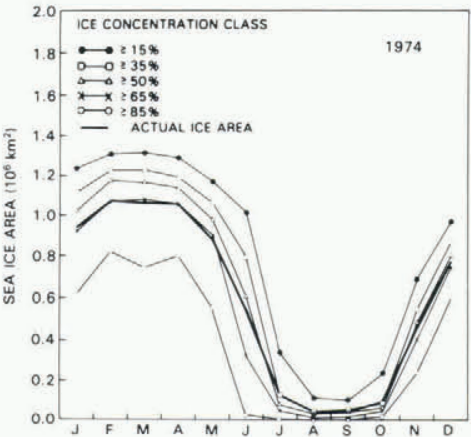

ARCTIC OCEAN

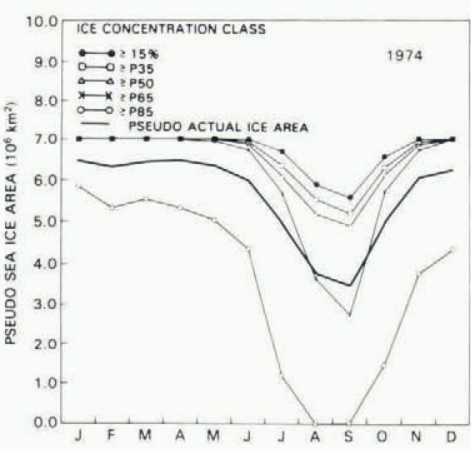

BERING SEA

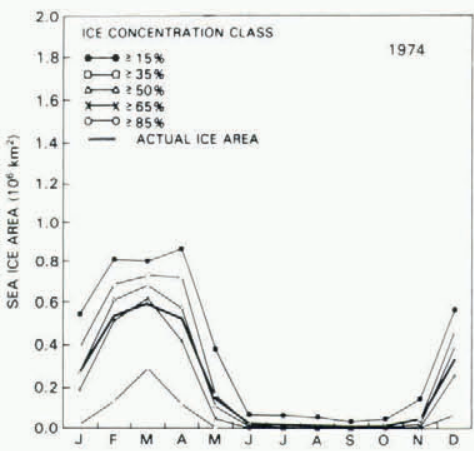

GREENLAND SEA

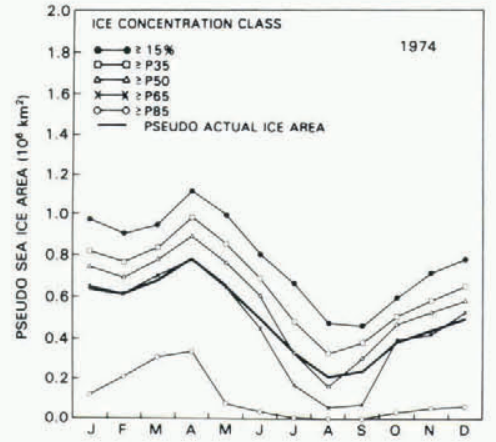

CANADIAN ARCHIPELAGO

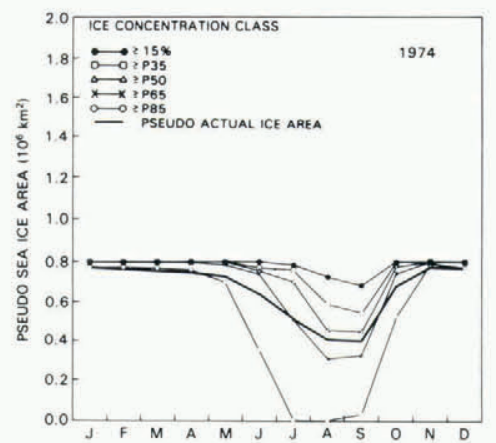

Fig.6. Annual cycles of (1) sea ice extents ( $\geqslant 15 \%),(2)$ areas with pseudo ice concentrations exceeding $35 \%, 50 \%, 65 \%$, and $85 \%$ (labelled $\geqslant \mathrm{P} 35, \geqslant \mathrm{P} 50, \geqslant \mathrm{P} 65$, and $\geqslant \mathrm{P} 85$, respectively, for regions with multiyear ice), and (3) pseudo actual ice areas, for each of the regions identified in Fig.5 and for the sum of the regions. In regions with no or almost no multiyear ice (the Sea of Okhotsk, Bering Sea, Hudson Bay, and Baffin Bay/Davis Strait), the "pseudo" qualifier is unnecessary and is therefore omitted.

Transpolar Drift Stream, which proceeds across the Arctic Basin from near the Siberian coast and out of the Arctic through the Fram Strait passage between Greenland and Svalbard. Both the multiyear ice transported from the Arctic and the first-year ice formed in the Greenland Sea are carried south along the east coast of Greenland by the East Greenland Current, accounting for the prominent southward extension of the ice cover in this region throughout the year (Fig.2). The annual cycle of ice in the Greenland Sea (Fig.6) is unusual in that there is a late but strong peaking of the ice cover in April and an earlier midwinter decrease of ice from January to February with only a slight rebounding from February to March.

The Kara and Barents Seas also experienced a midwinter decrease in ice extent, from February to March, in 1974 although the peak afterwards was not as prominent as the April peak for the Greenland Sea (Fig.6). The Kara and Barents Seas provide an interesting contrast in that the Barents Sea is subject to the warm water inflow from the northward flowing Norwegian Current, whereas the Kara
Sea is effectively blocked from that inflow by the island of Novaya Zemlya. The result is an almost total absence of ice in most of the Barents Sea throughout the year, in spite of the high latitudes and in spite of the very heavy ice cover in the adjacent Kara Sea for all except the late summer months (Fig.2).

Both the Arctic Ocean and the Canadian Archipelago are almost fully ice covered from November to May (Figs 2 and 6). The September minimum ice extent in each of these two regions exceeds $80 \%$ of the maximum ice extent, indicating a much smaller seasonal cycle of percentage ice cover than in any of the other regions. This also suggests a greater percentage of multiyear ice and the accompanying complications in interpreting the microwave brightness temperatures. From Figs 1 and 2, the retreat of the Arctic ice from the coasts in summer is clearly greater in the eastern hemisphere than in the western hemisphere, and the retreat of the ice in the Archipelago is clearly greatest in the southern passageways, with the exception of the southern Gulf of Boothia at about $86^{\circ} \mathrm{W}, 69^{\circ} \mathrm{N}$. 


\section{DISCUSSION AND SUMMARY}

The Nimbus 5 ESMR data provide a detailed depiction of the annual cycle of global sea ice coverage. In this paper we present this cycle for the north polar region for 1974 . The ESMR data reveal that the sea ice extent in the eight regions of the Northern Hemisphere identified in Fig.5 fluctuated in 1974 from a minimum of $7.6 \times 10^{6} \mathrm{~km}^{2}$ in September to a maximum of $14.4 \times 10^{6} \mathrm{~km}^{2}$ in March. The data also reveal that the sea ice cycle includes considerable interannual variability and interregional contrasts.

Many of the large-scale latitudinal asymmetries in the extent of the ice visible in Figs 1 and 2 are consistent from year to year (Parkinson and others 1987), and the consistencies are in many cases readily explained by ocean currents and bathymetry. In particular, currents with major impacts include the warm, north-flowing Norwegian, West Greenland, and West Kamchatka currents, which prevent or delay ice formation in the Barents Sea, immediately southwest of Greenland, and along the west coast of the Kamchatka Peninsula, respectively, and the cold south-flowing East Greenland and Labrador currents, which transport ice far to the south along the east coasts of Greenland and Canada.

There are other features of the ice cover which are not consistent from year to year. For instance, the February ice extent in the Sea of Okhotsk, $0.66 \times 10^{6} \mathrm{~km}^{2}$ in 1974 (Fig.6), was much higher in 1973, then being $1.09 \times 10^{6}$ $\mathrm{km}^{2}$. This and many of the other regional interannual contrasts in the ice can be explained by interannual differences in the atmospheric pressure and wind fields. In particular, for the case mentioned, the Siberian High pressure system was a more dominating influence over the Sea of Okhotsk in 1973 than in 1974, bringing in very cold air from northern Siberia.

Although the ESMR data set is too short to identify any long-term climate trends, the fact that the microwave data enable a very clear depiction throughout the year of global sea ice coverage establishes their usefulness for the future for identifying and confirming both major and smaller-scale changes in the climate system. The ESMR data reveal no systematic trend in the overall area of Northern Hemisphere ice coverage over the four years 1973-1976, but the extended data set possible from continued collection of global microwave data will contribute to the accumulating information on the Earth's climatic components and their seasonal and interannual variabilities.

\section{REFERENCES}

Campbell W J, Gloersen P, Zwally H J 1984 Aspects of Arctic sea ice observable by sequential passive microwave observations from the Nimbus-5 satellite. In Dyer I, Chryssostomidis C (eds) Arctic technology and policy. Washington, DC, etc, Hemisphere Publishing/McGraw-Hill International: $197-222$

Carsey F D 1982 Arctic sea ice distribution at end of summer 1973-1976 from satellite microwave data. Journal of Geophysical Research 87(C8): 5809-5835

Cavalieri D J, Parkinson C L In press On the relationship between atmospheric circulation and the fluctuations in the sea ice extents of the Bering and Okhotsk seas. Journal of Geophysical Research

Crane R G, Barry R G, Zwally H J 1982 Analysis of atmosphere-sea ice interactions in the Arctic basin using ESMR microwave data. International Journal of Remote Sensing 3(3): 259-276

Mätzler C, Olaussen T, Svendsen E 1983 Microwave and surface observations of water and ice carried out from $R / V$ Polarstern in the marginal ice zone north and west of Svalbard. Bergen, University of Bergen. Geophysical Institute

Parkinson C L, Gratz A J 1983 On the seasonal sea ice cover of the Sea of Okhotsk. Journal of Geophysical Research 88(C5): 2793-2802
Parkinson C L, Comiso J C, Zwally H J, Cavalieri D J, Gloersen P, Campbell W J 1987 Arctic sea ice, 1973-1976: satellite passive-microwave observations. Washington, DC, National Aeronautics and Space Administration (NASA SP-489)

Zwally H J, Comiso J C, Parkinson C L, Campbell W J, Carsey F D, Gloersen P 1983 Antarctic sea ice, 1973-1976: satellite passive-microwave observations. Washington, DC, National Aeronautics and Space Administration (NASA SP-459) 